\title{
Lifestyle modification for the management of atrial fibrillation
}

\author{
Yehia Fanous MD, Paul Dorian MD
}

Cite as: CMAJ 2020 November 16;192:E1469. doi: 10.1503/cmaj.201084

\footnotetext{
Weight loss, achieved and sustained through diet and exercise, is 1 associated with fewer atrial fibrillation recurrences ${ }^{1}$

Trials showing the benefit of weight loss (in combination with other strategies for managing risk factors) in atrial fibrillation have primarily used highprotein, low-glycemic-index diets, along with low-intensity exercise, to achieve reductions in body mass index (BMI). ${ }^{1,2}$ Patients with intermittent atrial fibrillation and $B M I \geq 27 \mathrm{~kg} / \mathrm{m}^{2}$ achieved the greatest increase in arrhythmia-free survival with a sustained weight loss of $\geq 10 \%$ of body weight (number need to treat $[\mathrm{NNT}]=4.8){ }^{1-3}$
}

2

Recreational exercise confers cardioprotective benefits in atrial fibrillation independently of weight loss ${ }^{1-3}$

Observational studies show that exercise, at any recreational intensity, is associated with reduced risk of developing atrial fibrillation, and improved symptom control in patients with persistent atrial fibrillation. ${ }^{1,3,4} \mathrm{~A}$ useful goal is to progressively increase to $200 \mathrm{~min} / \mathrm{wk}$ at moderate intensity (1000 metabolic equivalents [METs]), which is associated with an approximately $10 \%$ decrease in risk of incident atrial fibrillation. ${ }^{1,3}$

Reducing alcohol intake, in individuals who consume $\geq 14$ drinks

per week, is associated with a decreased burden of atrial fibrillation and decreased related hospital admissions ${ }^{1-3,5}$

There is conflicting evidence as to whether a linear dose-response relationship or a threshold effect exists between alcohol consumption and risk of atrial fibrillation. ${ }^{1,3}$ In a recent randomized controlled trial, abstinence in moderate drinkers ( $17 \pm 8$ drinks/wk) with intermittent atrial fibrillation was associated with reduced recurrence (NNT $=5) .{ }^{1}$ For patients who consume moderate to heavy amounts of alcohol, especially with binge drinking, it is appropriate to counsel them to reduce their intake.

Smoking cessation is recommended as part of strategies

for preventing and managing atrial fibrillation ${ }^{1}$

A dose-dependent relationship has been suggested between smoking and atrial fibrillation. ${ }^{1}$ Moreover, smoking is strongly associated with the development of chronic obstructive pulmonary disease, an important risk factor for atrial fibrillation. ${ }^{1}$

5 Limiting caffeine intake is unlikely to be useful in reducing atrial fibrillation incidence or burden ${ }^{1,3}$

No evidence exists to suggest that limiting habitual caffeine intake confers any benefit in reducing the risk of atrial fibrillation. ${ }^{1}$

\section{References}

1. Chung MK, Eckhardt LL, Chen LY, et al.; American Heart Association Electrocardiography and Arrhythmias Committee and Exercise, Cardiac Rehabilitation, and Secondary Prevention Committee of the Council on Clinical Cardiology; Council on Arteriosclerosis, Thrombosis and Vascular Biology; Council on Cardiovascular and Stroke Nursing; Council on Lifestyle and Cardiometabolic Health. Lifestyle and risk factor modification for reduction of atrial fibrillation: a scientific statement from the American Heart Association. Circulation 2020;141:e750-72.

2. Pathak RK, Middeldorp ME, Meredith M, et al. Longterm effect of goal-directed weight management in an atrial fibrillation cohort: a long-term follow-up study (LEGACY). J Am Coll Cardiol 2015;65:2159-69.

3. Wingerter R, Steiger N, Burrows A, et al. Impact of lifestyle modification on atrial fibrillation. Am J Cardiol 2020;125: 289-97.

4. Svedberg N, Sundström J, James S, et al. Long-term incidence of atrial fibrillation and stroke among crosscountry skiers. Circulation 2019;140:910-20.

5. Gémes K, Malmo V, Laugsand LE, et al. Does moderate drinking increase the risk of atrial fibrillation? The Norwegian HUNT (Nord-Trøndelag Health) study. J Am Heart Assoc 2017;6:e007094.

\section{Competing interests: None declared.}

This article has been peer reviewed.

Affiliations: Department of Medicine (Fanous), University of Western Ontario, London, Ont.; Division of Cardiology (Dorian), Department of Medicine, St. Michael's Hospital; Faculty of Medicine (Dorian), University of Toronto, Toronto, Ont.

Correspondence to: Paul Dorian, pauldorian@unityhealth.to

CMAJ invites submissions to "Five things to know about ..." Submit manuscripts online at http://mc.manuscriptcentral.com/cmaj 